\title{
Supplemental Multimedia Online Learning Tool (SMOLT) in Engineering Education
}

\section{Dr. Lulu Sun, Embry-Riddle Aeronautical Univ., Daytona Beach}

Lulu Sun is an associate professor in the Department of Freshman Engineering at Embry-Riddle Aeronautical University, where she has taught since 2006. She received her B.S. degree in Mechanical Engineering from Harbin Engineering University (China), in 1999, and her Ph.D. degree in Mechanical Engineering from University of California, Riverside, in 2006. Before joining Embry-riddle, she worked in the consulting firm of Arup at Los Angeles office as a fire engineer. Her research interests include engineering education and its pedagogies. She is a professional member of the Society of Fire Protection Engineer, and a member of American Society of Engineering Education.

\section{Cassandra Gribbins, Embry-Riddle Aeronautical University}

Cassandra is a mechanical engineering graduate student of Embry-Riddle Aeronautical University, Daytona Beach, Florida. She obtained her undergraduate degree in aerospace engineering with minors in computer aided design and human factors in 2007, also at Embry-Riddle Aeronautical University. Her graduate study is focusing on additive manufacturing and plastics design. She has participated in STEM Outreach events and has been a counselor for the Girls Exploring Math and Science summer camp.

\section{Dr. Ian T Ferguson, University of North Carolina, Charlotte}

I am currently a Professor and the Chair of Electrical and Computer Engineering at the University of North Carolina at Charlotte (UNC Charlotte). Prior to this I was a Professor in the School of Electrical and Computer Engineering and the School of Materials Science and Engineering at the Georgia Institute of Technology (Georgia Tech) and the Director for the Focused Research Program on Next Generation Lighting. Prior to joining Georgia Tech I have had leadership positions in both academia and industry. My research has focused on the area of wide bandgap materials and devices (emitters, detectors and electronics) using $\mathrm{GaN}$ and $\mathrm{ZnO}$, and developing these materials for energy and nanotechnology applications in the areas of illumination, solar power, spintronics, and nuclear detection. I have received competitive research grants and contracts from NSF, AFOSR, ONR, ARO, DARPA, NASA, and others totaling over $\$ 25 \mathrm{M}$ as lead investigator in industry and academia. As an international educator and researcher with active collaborations in the US, Europe and Asia, I have authored over 440 refereed journal and conference papers (H-Index is 32), seven book chapters, and have edited fourteen conference proceedings, one book, and multiple patents. I have given over 300 invited and contributed talks and seminars throughout the US, Europe and Asia. I have been actively involved in the entrepreneurial process of establishing new companies. Since arriving at Charlotte I co-founded and I am the Chairman of the Board for PiES, Project for innovation, Energy and Sustainability, a non-profit green business incubator that incubated seven companies. I am a Fellow of Institute of Electrical and Electronic Engineering (IEEE), Institute of Physics (FInstP), and the International Society for Optical Engineering (SPIE). 


\section{Supplemental Multimedia Online Learning Tool (SMOLT) in Engineering Education}

Abstract - This paper introduces the use of multimedia tools to create an online self-study environment to supplement the classroom instruction in engineering courses such as Graphical Communications. The topics in this course extend from hand sketching demonstrations to solid model creation using CAD software such as CATIA. Webcam, tablet PC, and Camtasia software were used to capture live examples and the recorded screencasts were posted in Blackboard. Supplemental Multimedia Online Learning Tools (SMOLT) provide students an efficient way to review the topics covered in the class, in that hand sketching and complex CAD models are often difficult to interpret through words and pictures alone. The positive survey results reflect an initial success of using multimedia tools to supplement the classroom instruction.

Keywords: multimedia, CAD, online, video

Introduction

This paper reports the development and use of a multimedia online learning tool to create an online self-study environment to supplement the classroom instruction in engineering courses; the Supplemental Multimedia Online Learning Tool (SMOLT). Multimedia forms of obtaining information have been widely adopted by students when available in both traditional and nontraditional learning environments such as Massive Open Online Courses (MOOCs). The value of a multi-media approach to supplement classroom learning is well understood however its implementation and long-term assessment are still limited. Moreover, while MOOCs has been used to record lectures it does not mimic other aspects of the student-faculty interaction for a more complete educational experience that is recognized in various educational taxonomies.

Multimedia forms of obtaining information have been recognized in the last 20 years as a way to supplement classroom instruction. It has been widely adopted by students when available and has proved to be an efficient way to achieve students learning outcomes ${ }^{1-2}$. Its value has been seen in both traditional and non-traditional learning environments. Students at the United States Military Academy needed greater control, flexibility, and utility as to when and how they learn course material. This was provided by network-based multimedia presentations and hypertext documents, primarily the classroom material ${ }^{3}$. Others have taken a more focused and integrated approach by developing topics related software to address a particular issue in students learning. The study of engineering dynamics is difficult with traditional classroom teaching tools since they cannot show motion therefore packages such as BEST (Basic Engineering Software for Teaching) Dynamics were produced ${ }^{4}$. These individual initiatives can also be developed into university-wide multimedia instruction enterprises that provide media-based resources to assist faculty members across multiple disciplines ${ }^{5}$. However, the ability to distribute and share these resources were limited by the delivery system in the early 1990's and, for example, the freshman engineering graphics class at UC Berkeley was given an interactive multimedia CD. The approach was extremely well received, even in this format, and helped with the understanding of the course material ${ }^{6}$.

As increased internet bandwidth and new delivery systems became available, media-based teaching tools improved especially for engineering applications in which complex components 


\section{ASEE Annual Conference}

and assemblies are often difficult to visualize. One such approach was EDICS (Engineering Design Instructional Computer Program) which took the students through a series of interactive screens that included media such as pictures, animations, videos, and even games ${ }^{7}$. Multimedia courseware has also been used in teaching mathematics to increase the student's motivation when learning topics such as loci in two dimensions ${ }^{8}$. Researchers developed screencasts in thermodynamics, heat transfer, and fluids, material and manufacturing courses ${ }^{9-17}$. Purdue University makes mention of using the screen capture and video editing software, Camtasia Studio from TechSmith Corporation, to assess students through in-video quizzes ${ }^{18}$. In instances where English is not the primary language, ADA compliant captions can aid in comprehending the content of the video. Captions may also help viewers that are in noisy environments still understand what is being said in the video. The value of a multimedia approach to supplement classroom learning is well understood however its implementation is still limited.

In this work a series of SMOLTs, short 1-6 min videos, based on different fundamental engineering topics have been developed. These provide the students with an efficient way to review the topics covered in the class and should be transferrable across a range of engineering disciplines. These thoughtfully constructed screencasts provide step-by-step audio illustrations with captions, the creation of 3D model visualizations, pictures, and quizzes provide students with unlimited contact with the instructor. They are an effective supplement to classroom instruction that helps students with understanding the course material that can be more broadly implemented outside of Graphical Communications. Surveys taken for multiple classes showed that more than $95 \%$ of students who used this online resource 'liked' it.

\section{Understanding SMOLT}

A MOOC (Massive Open Online Course) is a form of distance education offered to students that can be geographically distributed around the world. The focus of MOOCs is to offer courses, typically taught by professors, to non-traditional students and has been championed by institutions such as MIT and Stanford ${ }^{19}$. MOOCs offer students who may have full-time jobs or who may not have the financial resources to attend a traditional university the ability to participate in many classes for free. However, these courses generally do not result in college credits toward a degree. A SPOC (Small Private Online Course) is a condensed program offered by Harvard University ${ }^{20}$. SPOCs are also free but have limitations on the number of students who can participate at one time. It is generally understood that students perform better in small, customizable groups, as opposed to MOOC, which offers a course to an unlimited number of students $^{20}$. More recently, universities such as Georgia Institute of Technology and Lesley University are taking supplemental instruction in higher education a step further than the standard MOOC model. These programs will give students the opportunity to earn their degrees on their own terms, and at a much more affordable price ${ }^{21}$. For example, Georgia Institute of Technology will offer their OMSCS (Online Master of Science in Computer Science) degree for under $\$ 7,000.00$ starting in the spring semester of $2014^{22}$.

A number of taxonomies exist to help quantity educational aims and objectives, to delineate different types of learning and to show the transition between intermediate steps towards some type of expertise. One of the first and most used is Bloom's taxonomy ${ }^{23}$ has identified of three types of learning; cognitive, associated with mental skills, affective, associated with growth in feelings or emotional areas; and psychomotor, associated with manual or physical. A traditional 


\section{ASEE Annual Conference}

academic education focuses on the cognitive and in Bloom's taxonomy this has an additional hierarchical substructure that moves through knowledge, comprehension, application, analysis, synthesis, and evaluation. Other educational taxonomies such as SOLO (Structure of Observed Learning Outcome) have also been proposed and investigated ${ }^{24}$. This taxonomy proposes that learning complex material such as that often seen in engineering disciplines needs to be broken down into less complex tasks and later integrated to form a solid understanding of the subject. The SOLO taxonomy also stresses an important point that the learning process requires effort from both the educator and the student. In most of these models the traditional lecture, and by association MOOCs, typically only addresses the lower levels of learning in these taxonomies. The transition to higher levels of complexity in student's learning ability typically requires a more dialectic approach with an individualized interaction with the professor, in essence a cognitive apprenticeship. The Supplemental Multimedia Online Learning Tool (SMOLT) is the next logical step from the MOOCs since it will deliver the one-on-one interaction that the student has with the instructor using a dialectic approach. Moreover, the use of SMOLTs will enable hierarchical transitions towards expertise in some sense mimicking the journey of a smolt, a young salmon that migrates from fresh water to the sea, as the student also develops in their journey of learning.

Multimedia supplemental instruction in the traditional educational model offers students the opportunity to gain a more in-depth understanding of a specific topic. Supplements are offered in the form of short videos that capture the main focus of a lecture or a lab, thus giving students another focal point in which to review materials outside the classroom setting. Students who have difficulty understanding a particular aspect of the material will be better equipped to point out what areas of the broader subject they are having trouble with when consulting with the instructor or their classmates. In turn, the instructor will be better prepared to address consistent areas of concern within the framework of the lecture. SMOLT, as opposed to MOOC, offers traditional university students an additional learning tool for success. There are shared advantages, such as helping students develop better problem solving techniques and encourage students to create learning communities with classmates when reviewing the information ${ }^{19}$. The focus of SMOLT is to create a more personalized student experience when reviewing topics covered in the class. Students can use SMOLT as a way to reviews lectures or lab assignments multiple times to gain better clarity of the topic. This generation has become less focused on using text books or manuals but often watches how other people are doing things online, and then tries it themselves. They have also become good at processing multiple information streams adapting to the high tech forms of media which often require multitasking but typically with short attention spans. In addition, it has been found that when groups have reviewed videotapes of lectures, stop them every three minutes, discuss what have seen, and address questions or ambiguities at that time they typically outperformed the ones actually taking the classes live ${ }^{25}$. Accordingly, SMOLTs are short 1-6 min videos, in this instance based on different fundamental engineering topics, which will mimic a one-on-one interaction with instructor. Students who participate in supplemental learning such as SMOLT have a decrease in course drop outs rates by almost $50 \%$ and often have better test scores ${ }^{26}$. However, the most effective methods must be investigated to find best media or combination of media, i.e. blended learning ${ }^{27}$, for the subject matter.

Implementation of SMOLT 


\section{ASEE Annual Conference}

Graphical Communications is a core course taught to all the first-year undergraduates at EmbryRiddle Aeronautical University and was chosen for the implementation of SMOLT. It is designed to familiarize the students with the basic principles of drafting and engineering drawing, to improve three dimensional (3D) visualization skills, and to teach the fundamentals of a computer aided design. The students meet the instructor twice a week during this three-credithour semester course with each class lasting two hours. The first hour of each class is the scheduled lecture time after which the students are allowed to complete their assigned homework and ask questions as needed. The students learn the principles of orthographic projections and apply the principles to multi-view drawings by hand during the first four weeks of a fourteenweek semester. A 3D computer aided parametric modeling tool, CATIA, is then introduced after hand drawing, followed by auxiliary and section views, dimensioning, and tolerances. However, the students often struggle with visualization at the beginning of the semester; especially, how to complete an incomplete or missing orthographic view and the isometric view of the orthographic projections. If this lack of understanding continues the students will quickly fall behind and will have a difficult time transitioning to understanding the 3-D computer aided parametric modeling tool. The relatively short class time means that not all students get the immediate help they need. In addition, many of them do not follow up during office or tutoring hours for additional assistance. Since it is early in their university career they often are not mature enough to admit they are unsure of the material and need help.

Similar classes exist at UNC Charlotte but this paper focus initially on the data obtained from Embry-Riddle Aeronautical University.

Video Files Creation

LifeCam Studio® from Microsoft, and a Samsung tablet PC were used to record and better illustrate the more challenging concepts of hand sketching. Camtasia Studio ${ }^{\circledR}$ from Techsmith was used to capture CATIA model problems and to post process demonstrating the use of the 3D CAD software. The video files, approximately 10 minutes long, were saved as Mpeg4 HD files and posted in Blackboard via the Kaltura ${ }^{\circledR}$ video application. A similar approach has been taken at both institutions.

The topics covered include engineering scales, orthographic projections, section views, and auxiliary views. Figure 1(a) shows a screencast which was captured using LifeCam Studio®, the audio illustration explains the layout of the given views and how to complete the missing top view and the corresponding isometric view. The cubes were used to construct the 3-D model to visualize the different views and the relationship between the orthographic views and the isometric view. Figure 1(b) describes a section view sketching screencast which was created by using Camtasia Studio® to record the hand writing on OneNote with a Samsung tablet PC and a stylus pen.

Figures 2 and 3 document CATIA, Camtasia Studio ${ }^{\circledR}$ was used to capture the CATIA screens to demonstrate how to create a 3D solid model. Figure 2 (a) shows how to use paint software to illustrate the given two orthographic views and which view should be selected to create an efficient 3D model Figure 2(b) demonstrates how to use a yellow magnifier in Camtasia to highlight the icon which would be used to create the 3D part. Figure 3 (a) describes how to use a zoom-n-pan tab to add zoom and pan animations to video files. Figure 3 (b) was used to 
demonstrate how to create 2D drafting file using CATIA. It was found using animation, pictures, and audio narrations for hand sketching or CATIA 3D models facilitated another types of learners, visual learners to further improve their comprehension ${ }^{28}$.

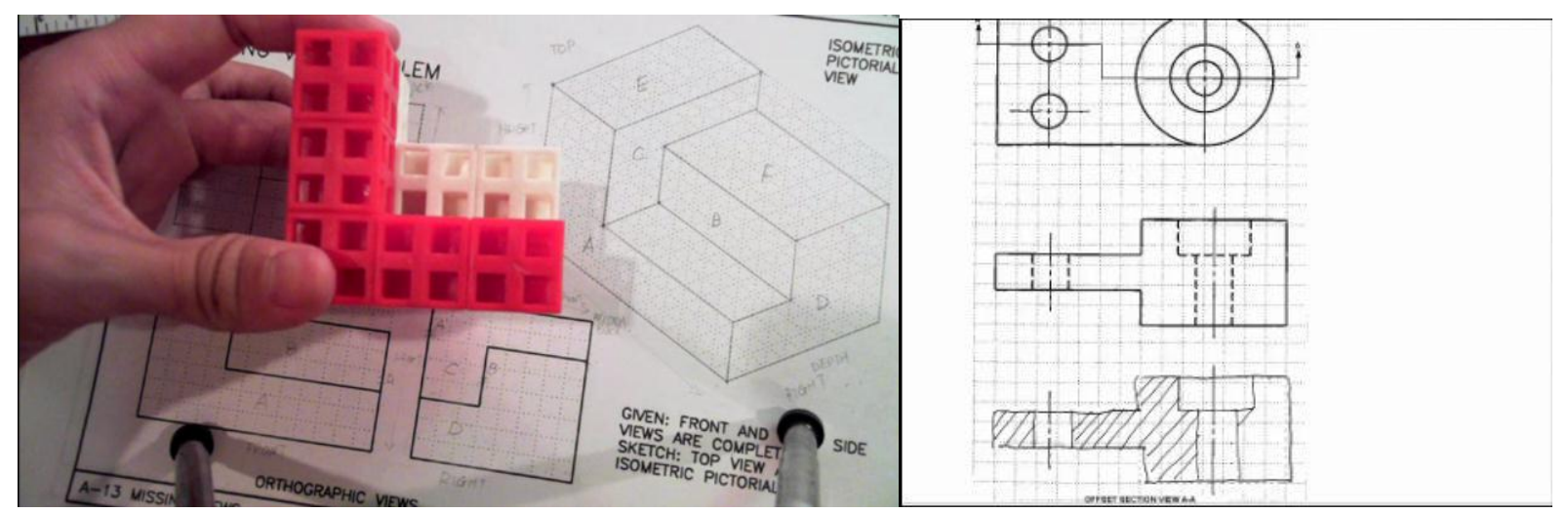

(a)

(b)

Figure 1. (a) hand sketching screencast by LifeCam Studio (b) hand sketching screencast by Samsung tablet PC

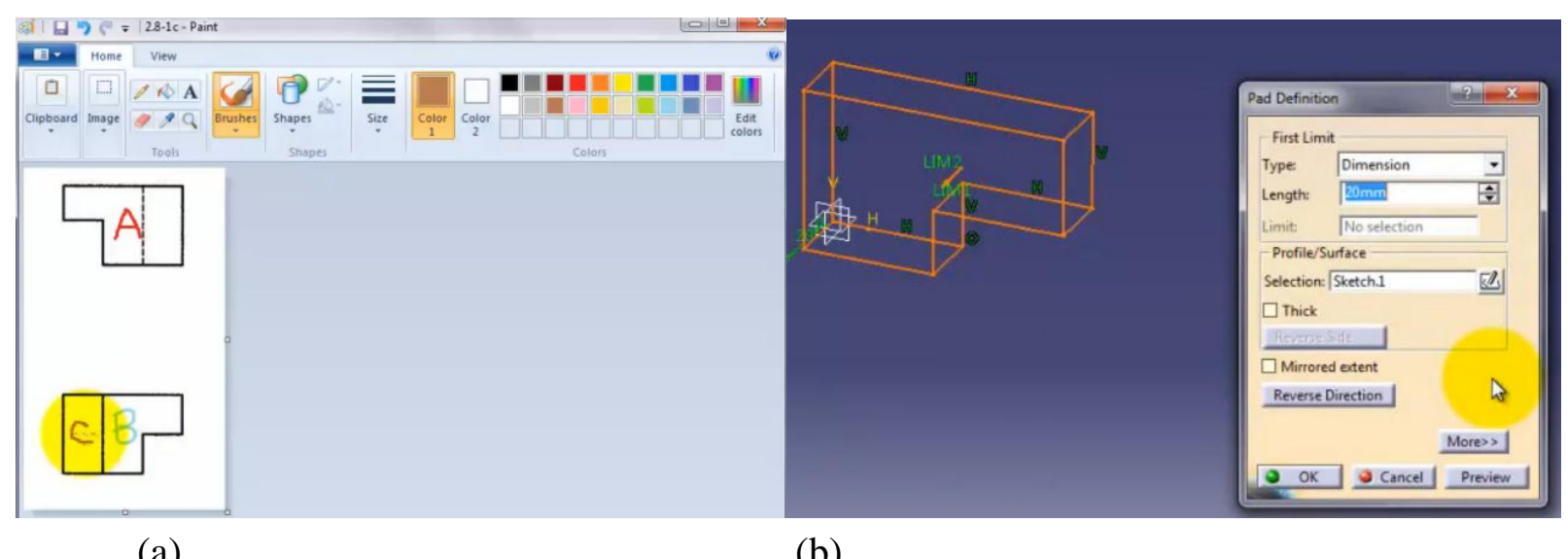

Figure 2. (a) CATIA screen and paint screen; and (b) CATIA model

Captions were implemented using Camtasia's speech-to-text feature that interprets the audio of the video into captions with a screenshot shown in Figure 4 (a). They were edited afterwards as technical jargon is not recognized through general speech to text software. An option to format captions into ADA compliant settings was used. The captions could either be overlain on the video or positioned under the video. Due to the CATIA toolbars covering the lower portion of the screen, the option for the captions under the video was used as illustrated in Figure 4 (b).

The quiz feature was utilized to include interactive quizzes in the videos. Figure 6 shows the four types of questions available: (a) multiple choice, (b) fill in the blank, (c) true/false, and (d) short answer. The short answer option can be used to allow the students to provide feedback on the quality of the video. Challenges encountered included adjusting the video fit within the window and having the quiz itself display. 


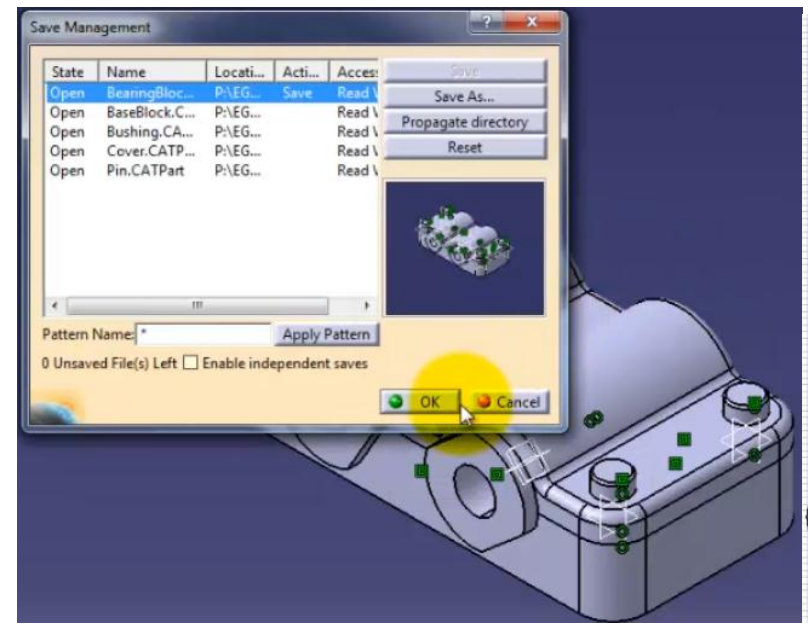

(a)

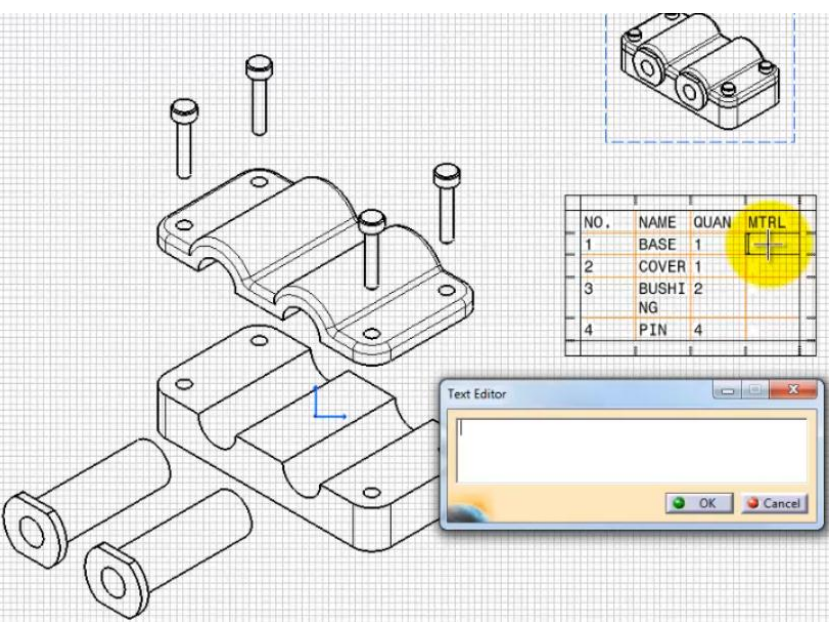

(b)

Figure 3. (a) A zoom-n-pan screenshot; and (b) CATIA drafting file

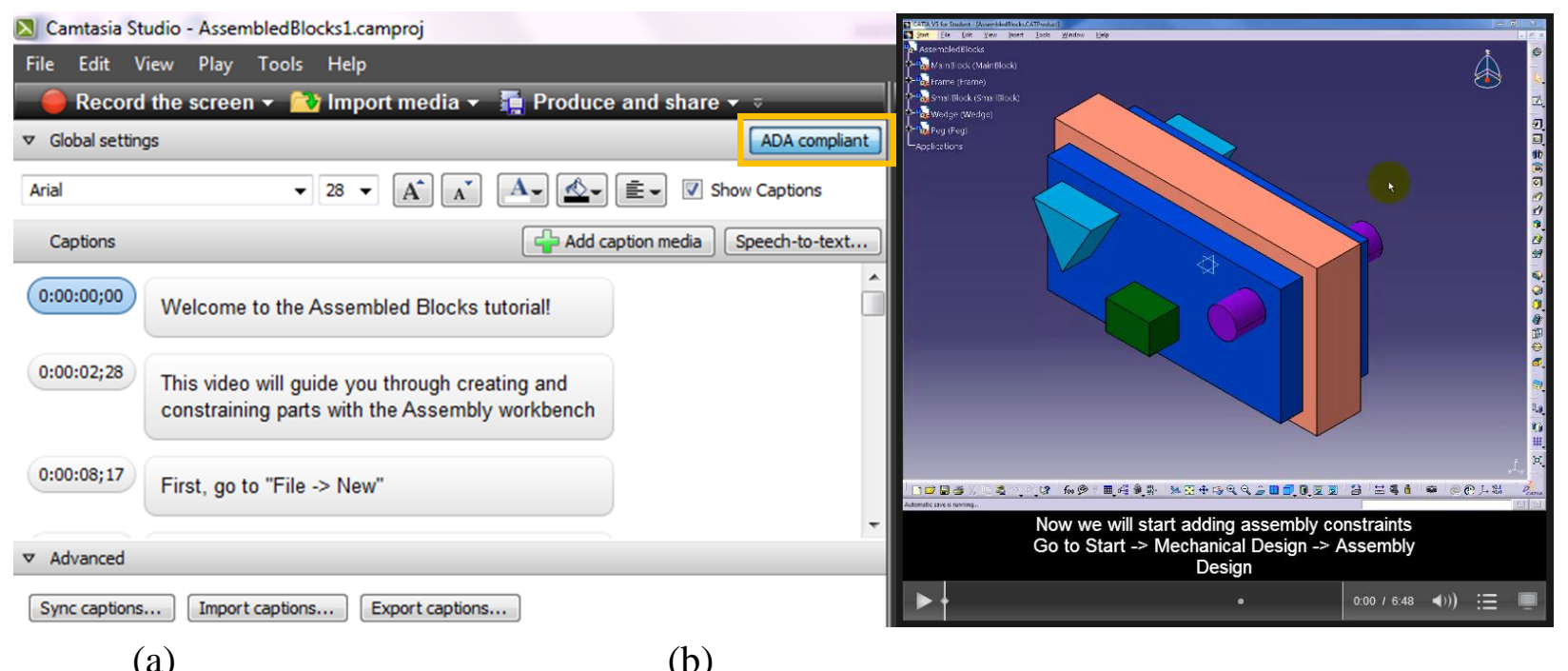

(a)

(b)

Figure 4. (a) Camtasia caption editor highlighting ADA compliant button, (b) produced video with captions

To display the quiz format in Blackboard, a tutorial from Purdue University was used as guidance to develop the necessary custom settings for the desired format, which included a Shareable Content Object Reference Model (SCORM) output file ${ }^{29}$. SCORM is used as the industry standard for interoperability between learning content and learning management systems ${ }^{30}$. The SCORM output option was used to generate a zipped file that could be uploaded to Blackboard to retain the quiz feature as opposed to uploading just the Mp4 file, which does not allow the feature. Figure 7 shows screenshots from (a) choosing the custom production settings option on the first window of the production screen in Camtasia, (b) SCORM button option to enter settings, (c) option to select zip file production, and (d) the Blackboard upload 
option under the Build Content menu. An additional adjustment was to decrease the embedded video size to fit within the webpage as viewing the video in full screen disables keyboard input.

(a)

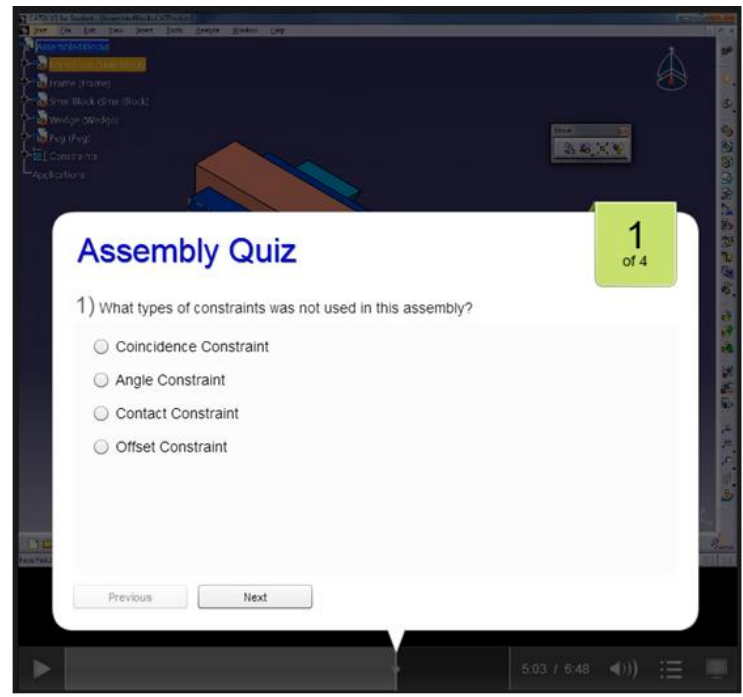

(c)

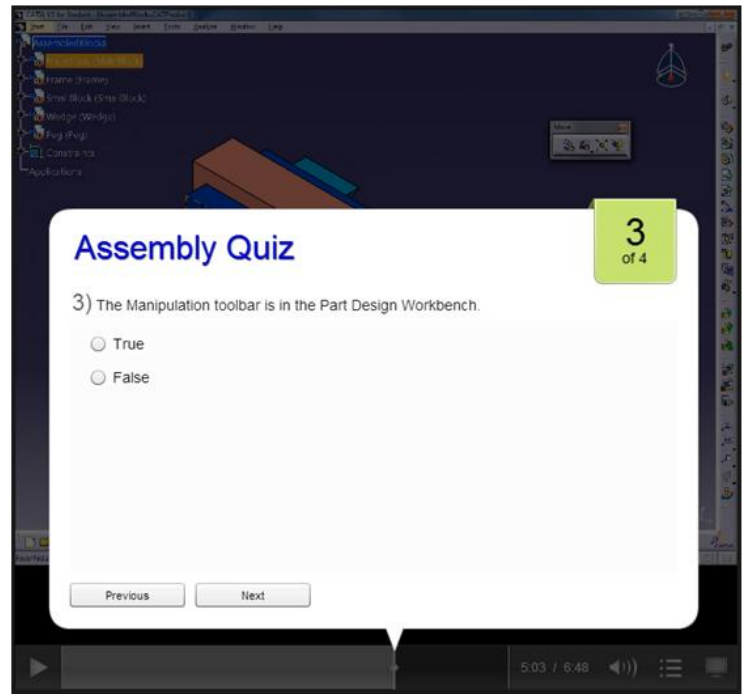

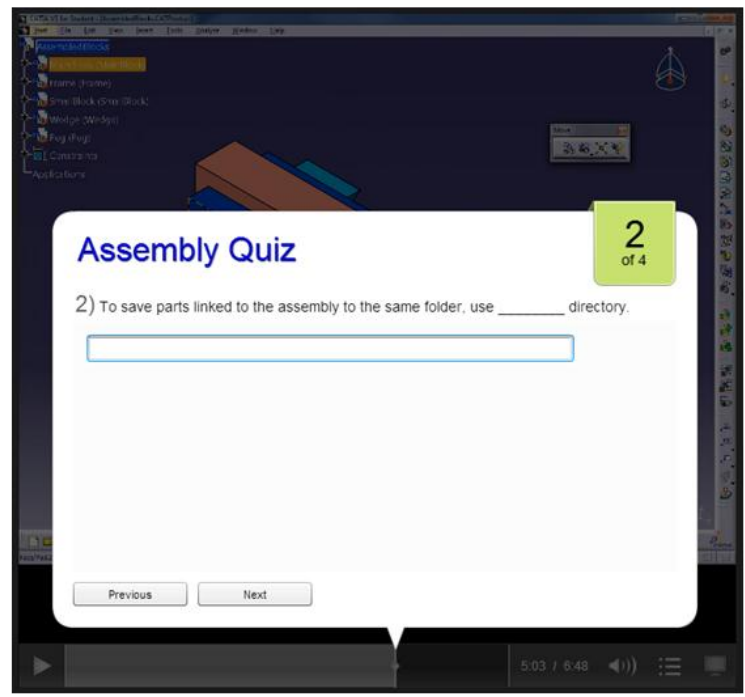

(b)

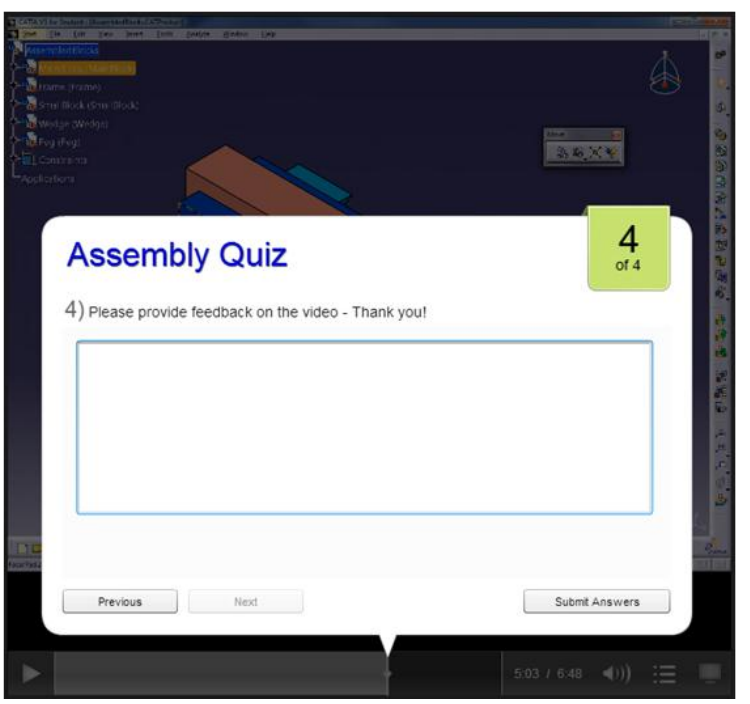

(d)

Figure 6. Types of quizzes with sample questions: (a) Multiple choice, (b) Fill in the blank, (c) True/False, (d) Short answer 
(a)

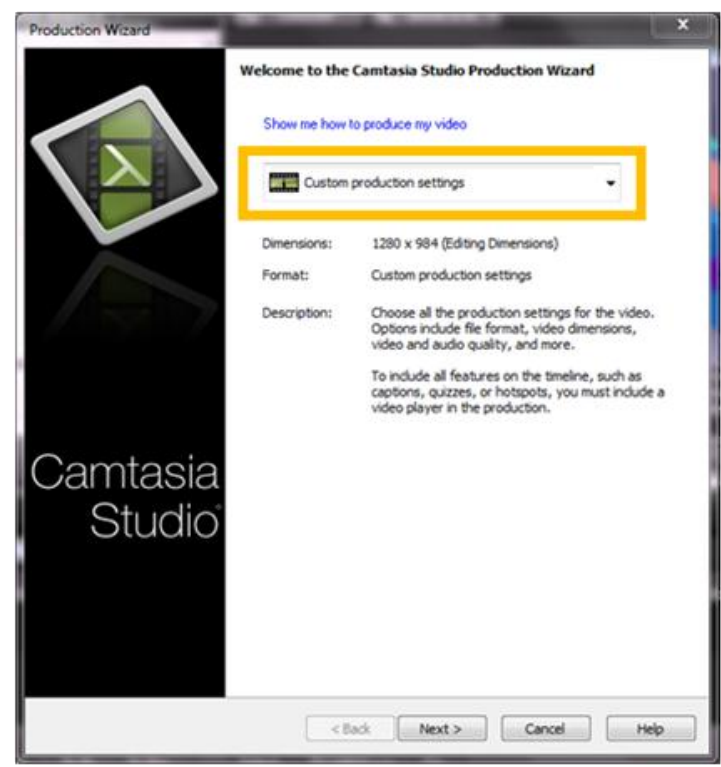

(c)

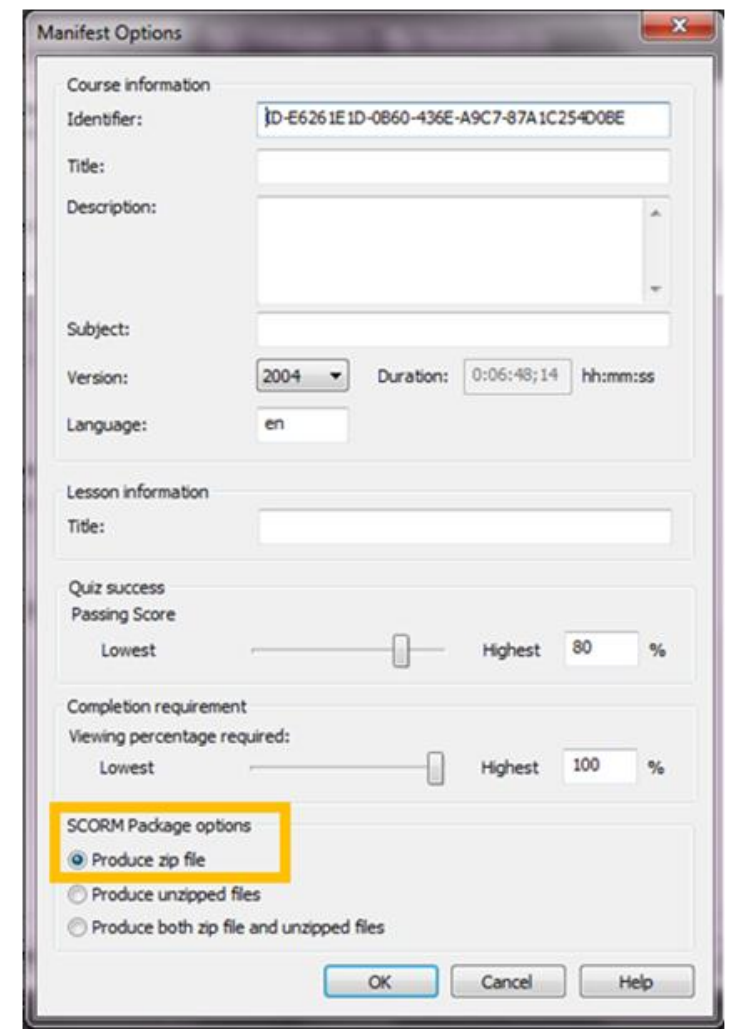

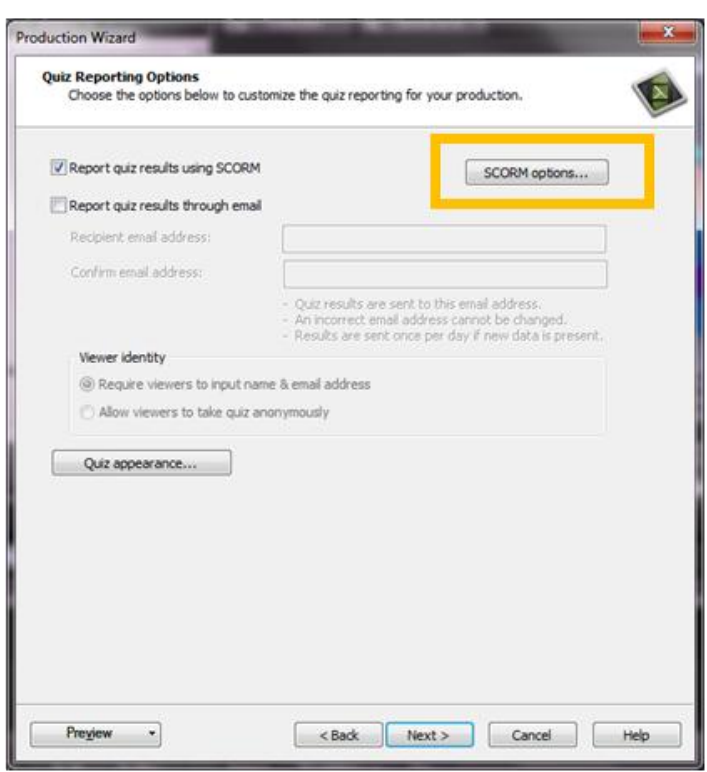

(b)

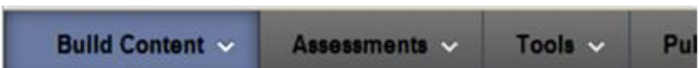

(d)

Figure 7. Production and upload specifics options: (a) Production Wizard first page highlighting custom settings option, (b) Quiz reporting options page highlighting SCORM options button, (c) SCORM options window highlighting zip file production option, (d) Blackboard screenshot highlighting Content Package selection under the Build Content tab

\section{Results and Discussion}

The survey was completed by 78 students in the fall 2012 semester, 55 students in the spring 2013, and 38 students in the fall 2013. The survey was given at the middle of the each semester 
and yielded positive results as shown in Figure 8. Figure 8 (a) presents the results for question one, which asked students if they watched the video files. $41 \%$ students in the fall 2012 semester, $43 \%$ students in the spring of 2013, and $70 \%$ students in the fall of 2013 watched the video files. The second question asked the students for the reasons if they did not watch the video files. Of those who did not watch the videos indicated they did not need to watch because either they fully understood the material covered in the class or they have the PDF tutorial which helped in understanding. Figure 8 (b), for the students who watched the videos, all but one 'extremely liked' or 'liked' them. The only one student, who did not like the material, stated the material in the videos was covered too quickly.

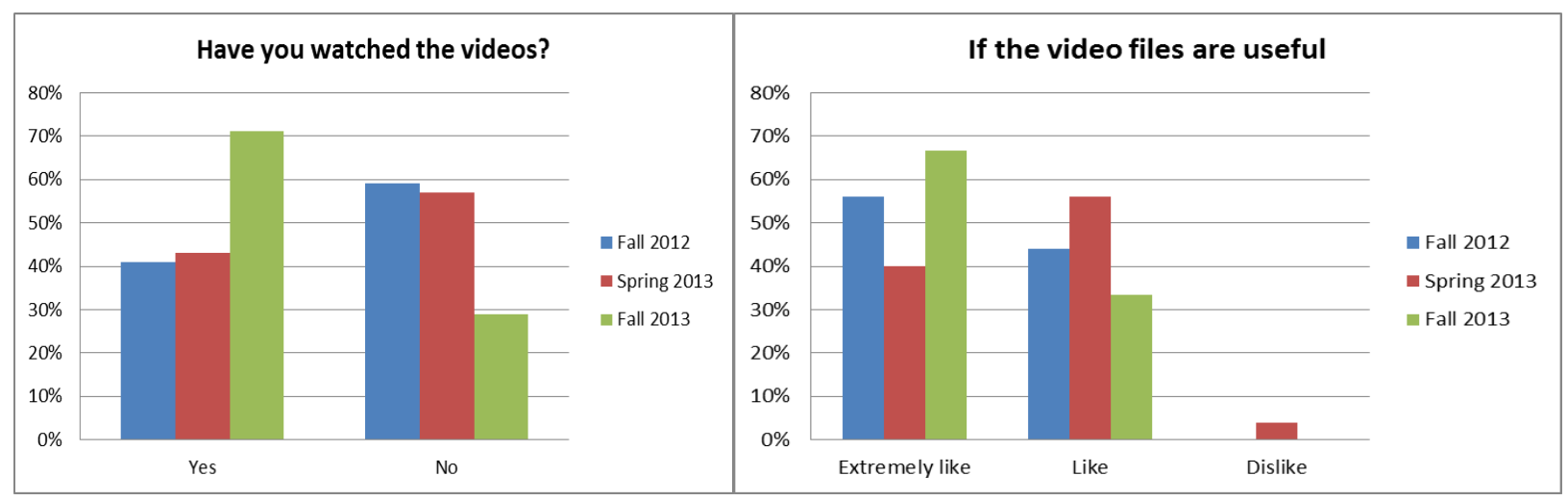

(a)

(b)

Figure 8. (a) A survey to check if students watched the videos; (b) Video files usefulness.

Conclusions and Future Work

SMOLT, a Supplemental Multimedia Online Learning Tool, offer students another approach to study hand sketching and CAD software that can often be initially difficult to learn or understand during the limited class period. The paper demonstrates that the video files help students better understand the graphics concepts, as these can often be difficult to visualize. The design intent via audio narration, pictures, animations, and the creation of 3D models can be more clearly shown. Further improvements will include a creation of a baseline video incorporating interactive features and then updating previous video files to incorporate new content and/or updating existing course content. Tracking the number of views to get a clear understanding of what video content does well to help guide the future video creation. Blackboard shows the potential of obtaining statistics on how many times the video was accessed and during what time of day including what day of the week. The addition of an interactive table of contents was attempted but technical requirements of using Camtasia's video player or TechSmith Smart Player, provided a challenge when uploading to Blackboard. The HTML file created that automatically uses the video player references Flash require security setting modification and further research.

\section{REFERENCES}

1. Huston, J. C., Barrance, P. J. and Heimcke, C. (1992). "Multimedia Courseware in the Instruction of Undergraduate Dynamics," $22^{\text {nd }}$ Annual Frontiers in Education Conference, Nashville, TN. 


\section{ASEE Annual Conference}

2. His, S. and Agogino, A. M. (1994). "The Impact and Instructional Benefit of Using Multimedia Case Studies to Teach Engineering Design," Journal of Educational Multimedia and Hypermedia, vol. 3, no. 3/4, pg. 351-376.

3. Carver, C. A. and Biehler, M. A. (1994). "Incorporating Multimedia and Hypertext Documents in an Undergraduate Curriculum," Proceedings Frontiers in Education 24th Annual Conference, San Jose, CA.

4. Flori, R. E. Jr. (1994). "Computer-Aided Instruction in Dynamics: Does it Improve Learning?," 24 ${ }^{\text {th }}$ Annual Frontiers in Education conference, San Jose, CA.

5. Chin, A., Robert, F. and Amy, R. (1996). "The Multimedia Instruction Initiative: Implications for Engineering Education," American Society for Engineering Education Annual Conference and Exposition, Washington, DC.

6. Lieu, K. D. (1999). "Using Interactive Multimedia Computer Tutorials for Engineering Graphics Education," Journal for Geometry and Graphics, vol. 3, no. 1, pg. 85-91.

7. Jimenez, C. (2006). “A Media-Based Engineering Design Teaching Tool: MIT's EDICS,” American Society for Engineering Education New England Section Annual Conference.

8. Zaini, Z. H. and Ahmad, W. F. W. (2010). "A Study on Students' Motivation in Learning Mathematics Using Multimedia Courseware,” IEEE, Information Technology (ITSim), International Symposium, Kuala Lumpur, MALAYSIA.

9. Falconer, J.L., Nicodemus, G., deGrazia, J., and Medlin, J.W. (2012). "Chemical Engineering Screencasts", Chemical Engineering Education, 46, 58-62.

10. Falconer, J.L., deGrazia, J., Medlin, J.W., Holmberg, M. (2009). "Using Screencasts in Chemical Engineering Courses," Chemical Engineering Education, 43, 302-305.

11. Falconer, J.L. (2004). "Use of ConcepTests and Instant Feedback in Thermodynamics," Chemical Engineering Education, 38(1), 64.

12. Falconer, J.L. (2007). "ConcepTests for a Chemical Engineering Thermodynamics Course," Chemical Engineering Education, 41(2), 107.

13. Millunchick, J. M. (2008). "Example of a Mini-Lecture Screencast on Dislocations," Retrieved from jmmg5.engin.umich.edu/dislocation/dislocations.html

14. Millunchick, J. M. (2009). "Example of a Homework Solution Screencast," Retrieved from jmmg5.engin.umich.edu/hw04/hw04.html

15. Pinder-Grover, T., Green, K., \& Millunchick, J.M. (2011). "The Efficacy of Screencasts to Address the Diverse Academic Needs of Students in a Large Lecture Course," Advances in Engineering Education, 2 (3).

16. Pinder-Grover, T., Millunchick, J. M., Bierwert, C., \& Shuller, L. (2009a). "Leveraging Screencasts to Strategically Clarify Unclear Materials Science Concepts," Paper presented at American Society for Engineering Education, Austin TX.

17. Pinder-Grover, T., Millunchick, J. M., Bierwert, C., \& Shuller, L. (2009b). "The Efficacy of Screencasts on Diverse Students in a Large Lecture Course," Paper presented at American Society for Engineering Education, Austin TX.

18. Mong, C. (2013). "What Can Camtasia Do for You?," Purdue University Instructional Development Center Blog, Retrieved from https://www.purdue.edu/learning/blog/?p=6303

19. Karsenti, T. (2013). "The MOOC - What the Research Says," International Journal Technologies in Higher Education.

20. Goral, T. (2013). “SPOCs May Provide What MOOCs Can't,” University Business.

21. Lesley University. (2013). "Interdisciplinary Studies Graduate Programs," Retrieved from http://www.lesley.edu/masters/interdisciplinary-studies/.

22. Georgia Tech College of Computing. (2013). "Georgia Tech Announces Massive Online Master's Degree in Computer Science". Retrieved from http://www.omscs.gatech.edu/announcement/.

23. Bloom, B. S., \& Krathwohl D. R. (1956). "Taxonomy of Educational Objectives: The Classification of Educational Goals, by a Committee of College and University Examiners. Handbook 1: Cognitive Domain," New York : Longmans.

24. Biggs, J. B., \& Collis, K. (1982) "Evaluating the Quality of Learning: the SOLO taxonomy," New York: Academic Press.

25. Brown, J.S. (2000). "Growing Up Digital: How the Web Changes Work Education, and the Ways People Learn," Change: The Magazine of Higher Learning, 11-20.

26. Malma, J., Bryngforsa, L., and Mörnera, L. (2011). "Supplemental Instruction for Improving First Year Results in Engineering Studies," Studies in Higher Education, 37(6), 655-666. 


\section{ASEE Annual Conference}

27. Osguthorpe, R. T., Graham, C. R. (2003). "Blended Learning Environments: Definitions and Directions," Distance Education 4, 227-233.

28. Felder, R. and Silverman, L. (1988). "Learning and Teaching Styles in Engineering Education," Engineering Education, vol. 78, no. 7, pg. 674-681.

29. Purdue University Calumet, (2013). "Camtasia Advanced Features,” Rechieved from http://webs.purduecal.edu/oit/files/2013/09/Camtasia-Lecture-Recording-with-Quizzes-revised-9-5-13.pdf.

30. Rustici Software, "SCORM Explained,” Rustici Software. 